\title{
Control Valve Device
}

National Cancer Institute

\section{Source}

National Cancer Institute. Control Valve Device. NCI Thesaurus. Code C50244.

A valve designed to regulate the flow of a fluid, especially one designed to operate in response to a signal from a control system. 